\title{
Use of nicotine replacement therapy and stop- smoking medicines in a national sample of Aboriginal and Torres Strait Islander smokers and ex-smokers
}

n 2012-2013, 44\% of Aboriginal and Torres Strait Islander adults smoked, 2.5 times the age-standardised prevalence among other Australian adults, and $26 \%$ were ex-smokers. ${ }^{1}$ Although the proportion of those who had ever smoked and had successfully quit was only $37 \%$, compared with $63 \%$ of other Australians, this had increased from $24 \%$ in $2002 .{ }^{1,2}$ Several types of nicotine replacement therapy (NRT; gum, patches, lozenges, sublingual tablets and inhalers) and two prescriptiononly stop-smoking medicines (SSMs; bupropion and varenicline) are available in Australia to assist cessation. ${ }^{3}$ All have been shown to increase the chance of successfully quitting, with varenicline and combinations of NRT being the most effective. ${ }^{4}$

Nicotine gum became available in Australia in the 1980s, followed by patches in the 1990s and other forms of NRT in the past decade. ${ }^{3}$ Over-thecounter availability of NRT occurred first in pharmacies, then supermarkets. Subsidised availability by prescription for patches followed listing with the Pharmaceutical Benefits Scheme (PBS) for veterans from 1994, Aboriginal and Torres Strait Islander people from 2009, and all others from 2011. Bupropion was listed on the PBS in 2001, and varenicline in 2008. ${ }^{3}$ Since 1999, Aboriginal health services in remote areas have been able to dispense these PBS items at no cost through Section 100 of the National Health Act $1953 .{ }^{5}$ In addition, since July 2010, many nonremote Aboriginal health services and general practices participating in the Indigenous Health Incentive of the Practice Incentives Program have been able to reduce or eliminate the copayment for all PBS medicines, including SSMs, for their Aboriginal and Torres Strait Islander patients. ${ }^{6}$

Clinical guidelines suggest that NRT, bupropion or varenicline be recommended to all dependent smokers who

\section{Abstract}

Objective: To examine the use of nicotine replacement therapy (NRT) and the stop-smoking medicines (SSMs) varenicline and bupropion in a national sample of Aboriginal and Torres Strait Islander smokers and recent ex-smokers.

Design, settings and participants: The Talking About The Smokes (TATS) project used a quota sampling design to recruit a nationally representative sample of 1721 smokers and ex-smokers who had quit $\leqslant 12$ months before from communities served by 34 Aboriginal community-controlled health services and one community in the Torres Strait. Baseline surveys were conducted from April 2012 to October 2013. These were compared with 1017 daily smokers from the general Australian population surveyed by the International Tobacco Control Policy Evaluation Project (ITC Project) from July 2010 to May 2011.

Main outcome measures: Past and intended use of NRT and SSMs, duration of use, and whether participants thought NRT and SSMs help smokers to quit.

Results: Compared with other daily Australian smokers, lower proportions of Aboriginal and Torres Strait Islander daily smokers had ever used any NRT or SSMs (TATS, 37\% v ITC, 58.5\%) or used them in the past year (TATS, $23 \%$ v ITC, $42.1 \%$ ). Nicotine patches were most commonly used by Aboriginal and Torres Strait Islander smokers and recent ex-smokers ( $24 \%)$, followed by varenicline (11\%) and nicotine gum (10\%); most (74\%) had got their last NRT at no cost. Among dependent Aboriginal and Torres Strait Islander daily smokers, those who were more socioeconomically advantaged were more likely than the disadvantaged to have used NRT or SSMs. Similar proportions of Aboriginal and Torres Strait Islander daily smokers and other Australian daily smokers said that NRT or SSMs help smokers to quit (TATS, 70\% v ITC, 74.2\%). Dependent Aboriginal and Torres Strait Islander smokers who had previously used NRT or SSMs were more likely to believe they help in quitting and to intend to use them in the future. Conclusion: Aboriginal and Torres Strait Islander daily smokers, particularly those who are most disadvantaged, are less likely to have used NRT or SSMs than other Australian daily smokers. Some of the barriers to use, including cost, are being overcome, but further improvements are possible.

are interested in quitting..$^{7-9}$ Here, we explore the use of these medicines and beliefs about them among a national sample of Aboriginal and Torres Strait Islander smokers and exsmokers. We also explore variation in their use among dependent smokers in this population, and make comparisons with smokers in the general Australian population.

\section{Methods}

The Talking About The Smokes (TATS) project surveyed 1643
Aboriginal and Torres Strait Islander smokers and 78 recent ex-smokers (who had quit $\leqslant 12$ months before), using a quota sampling design based on the communities served by 34 Aboriginal community-controlled health services (ACCHSs) and one community in the Torres Strait. It has been described in detail elsewhere. ${ }^{10,11}$ Briefly, the 35 sites were selected based on the distribution of the Aboriginal and Torres Strait Islander population by state or territory and remoteness. In 30 sites, we aimed to interview 50 smokers or recent 
1 Aboriginal and Torres Strait Islander use of nicotine replacement therapy (NRT) or stop-smoking medicines (SSMs)

\begin{tabular}{|c|c|c|c|c|c|c|}
\hline \multirow[b]{2}{*}{ Smoking characteristic } & \multicolumn{3}{|c|}{ Ever used NRT or SSMs } & \multicolumn{3}{|c|}{ Used NRT or SSMs in the past year } \\
\hline & $\%$ (frequency)* & Odds ratio $(95 \% \mathrm{Cl})^{\dagger}$ & $P^{\ddagger}$ & $\%$ (frequency)* & Odds ratio $(95 \% \mathrm{Cl})^{\dagger}$ & $P^{\ddagger}$ \\
\hline \multicolumn{7}{|c|}{ Smokers and recent ex-smokers $(n=1721)$} \\
\hline \multicolumn{7}{|l|}{ Smoking status } \\
\hline Daily smokers & $37 \%(515)$ & 1.0 & $<0.001$ & $23 \%(318)$ & 1.0 & 0.001 \\
\hline Non-daily smokers & $17 \%(43)$ & $0.35(0.24-0.51)$ & & $12 \%(30)$ & $0.46(0.29-0.73)$ & \\
\hline Recent ex-smokers & $36 \%(28)$ & $0.94(0.57-1.55)$ & & $32 \%(25)$ & $1.59(0.95-2.66)$ & \\
\hline \multicolumn{7}{|c|}{ Daily smokers only $(n=1369)$} \\
\hline \multicolumn{7}{|c|}{ Heaviness of Smoking Index score } \\
\hline $\operatorname{Low}(0-1)$ & $30 \%(69)$ & 1.0 & $<0.001$ & $18 \%(42)$ & 1.0 & 0.06 \\
\hline Moderate (2-3) & $36 \%(284)$ & $1.34(1.00-1.81)$ & & $23 \%(184)$ & $1.39(0.92-2.08)$ & \\
\hline Heavy (4-6) & $45 \%(148)$ & $1.98(1.42-2.76)$ & & $27 \%(86)$ & $1.65(1.08-2.51)$ & \\
\hline \multicolumn{7}{|c|}{ RACGP criteria for dependence } \\
\hline None & $24 \%(38)$ & 1.0 & $<0.001$ & $13 \%(20)$ & 1.0 & $<0.001$ \\
\hline One & $27 \%(91)$ & $1.23(0.78-1.92)$ & & $17 \%(55)$ & $1.38(0.84-2.28)$ & \\
\hline Two & $35 \%(192)$ & $1.71(1.12-2.61)$ & & $21 \%(118)$ & $1.89(1.11-3.22)$ & \\
\hline All three & $59 \%(193)$ & $4.66(2.99-7.27)$ & & $39 \%(125)$ & $4.39(2.56-7.51)$ & \\
\hline
\end{tabular}

ex-smokers and 25 non-smokers, with equal numbers of women and men, and those aged $18-34$ and $\geqslant 35$ years. In four large city sites and the Torres Strait community, the sample sizes were doubled. People were excluded if they were aged under 18 years, not usual residents of the area, staff of the ACCHS or deemed unable to complete the survey. In each site, different locally determined methods were used to collect a representative, although not random, sample.

Baseline data were collected from April 2012 to October 2013. Interviews were conducted face to face by trained interviewers, almost all of whom were members of the local Aboriginal and Torres Strait Islander community. The survey was completed on a computer tablet and took 30-60 minutes. A single survey of health service activities was also completed at each site. The baseline sample closely matched the distribution of age, sex, jurisdiction, remoteness, quit attempts in the past year and number of daily cigarettes smoked reported in the 2008 National Aboriginal and Torres Strait Islander Social Survey (NATSISS). However, there were inconsistent differences in some socioeconomic indicators: our sample had higher proportions of unemployed people, but also higher proportions who had completed Year
12 and who lived in more advantaged areas. $^{10}$

The TATS project is part of the International Tobacco Control Policy Evaluation Project (ITC Project) collaboration. Interview questions were closely based on those in ITC Project surveys, especially the Australian surveys. ${ }^{12}$ We asked all smokers and recent ex-smokers whether they had ever used NRT or SSMs, and which they had used. For those who had used NRT, we asked if they were currently using it, when and for how long they last used it, where they got it and if it was free, and whether they would use it again in the future. We asked similar questions of those who had used SSMs. We asked all smokers and recent ex-smokers whether they thought NRT and SSMs help smokers to quit, and about their quit attempts and sociodemographic factors. The questions are described in detail in Appendix 1.

We used the Heaviness of Smoking Index (HSI) to assess dependence among daily smokers. The HSI was coded 0 to 6 based on the sum of the responses to two questions: cigarettes per day (CPD) and time to first cigarette (TTFC). These items were each coded as $0(0-10$ CPD; TTFC, $\geqslant 61 \mathrm{~min}), 1$ (11-20 CPD;
TTFC, 31-60 min), 2 (21-30 CPD; TTFC, $6-30 \mathrm{~min})$ or 3 ( $\geqslant 31 \mathrm{CPD}$; TTFC, $\leqslant 5 \mathrm{~min}) .{ }^{13}$ We categorised HSI as low (0-1), moderate (2-3) or high (4-6). ${ }^{14,15}$ We also assessed the three criteria for dependence in the Royal Australian College of General Practitioners (RACGP) cessation guidelines: TTFC $\leqslant 30 \mathrm{~min},>10 \mathrm{CPD}$, and withdrawal symptoms on previous quit attempts (defined in our sample as strong cravings during the most recent quit attempt). ${ }^{7}$

TATS project results were compared with those of 1017 daily smokers surveyed in Wave 8 of the Australian ITC Project between July 2010 and May 2011. The ITC Project survey was completed by random digit telephone dialling or on the internet, and included smokers contacted for the first time and those who were recontacted after completing surveys in previous waves. For respondents who had completed surveys in previous waves, the ITC Project questions about use of NRT or SSMs were different to the TATS project questions, so for these comparisons we included only the 189 daily smokers who were newly recruited to the ITC Project.

The project was approved by three Aboriginal human research 
2 Use of nicotine replacement therapy (NRT) or stop-smoking medicines (SSMs) by dependent Aboriginal and Torres Strait Islander smokers, * by sociodemographic factors $(n=1124)$

\begin{tabular}{|c|c|c|c|c|c|c|}
\hline \multirow[b]{2}{*}{ Sociodemographic factor } & \multicolumn{3}{|c|}{ Ever used NRT or SSMs } & \multicolumn{3}{|c|}{ Used NRT or SSMs in the past year } \\
\hline & $\%$ (frequency) $^{\dagger}$ & Odds ratio $(95 \% \mathrm{Cl})^{\ddagger}$ & $P^{\S}$ & $\%$ (frequency) $^{\dagger}$ & Odds ratio $(95 \% \mathrm{CI})^{\ddagger}$ & $P^{s}$ \\
\hline All dependent smokers & $39 \%(432)$ & & & $24 \%(270)$ & & \\
\hline Age (years) & & & 0.002 & & & 0.08 \\
\hline $18-24$ & $28 \%(59)$ & 1.0 & & $18 \%(39)$ & 1.0 & \\
\hline $25-34$ & $35 \%(102)$ & $1.43(0.98-2.08)$ & & $23 \%(67)$ & $1.35(0.91-2.02)$ & \\
\hline $35-44$ & $40 \%(112)$ & $1.78(1.12-2.83)$ & & $24 \%(65)$ & $1.37(0.85-2.23)$ & \\
\hline $45-54$ & $44 \%(86)$ & $2.07(1.29-3.33)$ & & $29 \%(55)$ & $1.78(1.12-2.83)$ & \\
\hline$\geqslant 55$ & $53 \%(73)$ & $3.00(1.79-5.01)$ & & $32 \%(44)$ & $2.13(1.25-3.64)$ & \\
\hline Sex & & & 0.18 & & & 0.11 \\
\hline Female & $41 \%(233)$ & 1.0 & & $27 \%(150)$ & 1.0 & \\
\hline Male & $36 \%(199)$ & $0.80(0.58-1.11)$ & & $22 \%(120)$ & $0.77(0.55-1.07)$ & \\
\hline Indigenous status & & & 0.14 & & & 0.76 \\
\hline Aboriginal & $40 \%(398)$ & 1.0 & & $25 \%(245)$ & 1.0 & \\
\hline Torres Strait Islander or both & $31 \%(34)$ & $0.70(0.44-1.12)$ & & $23 \%(25)$ & $0.93(0.56-1.52)$ & \\
\hline Labour force status & & & $<0.001$ & & & 0.02 \\
\hline Employed & $45 \%(166)$ & 1.0 & & $29 \%(105)$ & 1.0 & \\
\hline Unemployed & $30 \%(113)$ & $0.51(0.38-0.70)$ & & $20 \%(76)$ & $0.62(0.45-0.86)$ & \\
\hline Not in labour force & $41 \%(151)$ & $0.85(0.64-1.14)$ & & $24 \%(88)$ & $0.80(0.56-1.14)$ & \\
\hline Highest education attained & & & 0.001 & & & 0.03 \\
\hline Less than Year 12 & $35 \%(206)$ & 1.0 & & $21 \%(127)$ & 1.0 & \\
\hline Finished Year 12 & $38 \%(109)$ & $1.18(0.88-1.58)$ & & $26 \%(73)$ & $1.28(0.92-1.78)$ & \\
\hline Post-school qualification & $50 \%(115)$ & $1.90(1.36-2.67)$ & & $30 \%(68)$ & $1.58(1.12-2.23)$ & \\
\hline $\begin{array}{l}\text { Treated unfairly because Indigenous in } \\
\text { past year }\end{array}$ & & & 0.01 & & & 0.02 \\
\hline No & $43 \%(207)$ & 1.0 & & $28 \%(135)$ & 1.0 & \\
\hline Yes & $35 \%(214)$ & $0.71(0.54-0.92)$ & & $21 \%(129)$ & $0.68(0.50-0.93)$ & \\
\hline Remoteness & & & 0.002 & & & 0.03 \\
\hline Major cities & $43 \%(127)$ & 1.0 & & $29 \%(85)$ & 1.0 & \\
\hline Inner and outer regional & $41 \%(239)$ & $0.94(0.60-1.47)$ & & $25 \%(141)$ & $0.80(0.53-1.20)$ & \\
\hline Remote and very remote & $27 \%(66)$ & $0.50(0.31-0.80)$ & & $18 \%(44)$ & $0.54(0.34-0.86)$ & \\
\hline Area-level disadvantage & & & 0.03 & & & 0.02 \\
\hline 1st quintile (most disadvantaged) & $33 \%(141)$ & 1.0 & & $19 \%(81)$ & 1.0 & \\
\hline 2nd and 3rd quintiles & 41\% (189) & $1.40(1.01-1.94)$ & & $27 \%(122)$ & $1.54(1.09-2.17)$ & \\
\hline 4th and 5th quintiles & $45 \%(102)$ & $1.64(1.07-2.51)$ & & $30 \%(67)$ & $1.78(1.10-2.87)$ & \\
\hline $\begin{array}{l}\text { Local health service has dedicated } \\
\text { tobacco control resources }\end{array}$ & & & 0.006 & & & 0.003 \\
\hline No & $31 \%(97)$ & 1.0 & & $18 \%(57)$ & 1.0 & \\
\hline Yes & $42 \%(335)$ & $1.66(1.16-2.37)$ & & $27 \%(213)$ & $1.70(1.20-2.39)$ & \\
\hline
\end{tabular}

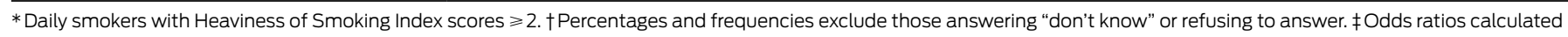
using simple logistic regression adjusted for the sampling design. $§ P$ values for the entire variable, using adjusted Wald tests.

ethics committees (HRECs) and two HRECs with Aboriginal subcommittees: Aboriginal Health \& Medical Research Council Ethics Committee, Sydney; Aboriginal Health Research Ethics Committee, Adelaide; Central Australian HREC, Alice Springs; HREC for the Northern Territory Department of Health and Menzies School of Health Research, Darwin; and the Western Australian
Aboriginal Health Ethics Committee, Perth.

\section{Statistical analyses}

We calculated the percentages and frequencies of responses to the TATS project questions, but did not include confidence intervals for these as it is not considered statistically acceptable to estimate sampling error in non-probabilistic samples. We compared results for daily smokers with those from the Australian ITC Project, which were directly standardised to the distribution of age and sex of Aboriginal and Torres Strait Islander smokers reported in the 2008 NATSISS.

Within the TATS project sample, we assessed the association between variables using logistic regression, with confidence intervals adjusted 
3 Aboriginal and Torres Strait Islander smokers and recent ex-smokers' beliefs about whether nicotine replacement therapy (NRT) and stop-smoking medicines (SSMs) help smokers to quit*

Do you think NRT and SSMs help smokers to quit?

\begin{tabular}{|c|c|c|c|c|c|}
\hline \multirow[b]{2}{*}{ Smoker characteristics } & \\
\hline & Very much & Somewhat & Not at all & $\begin{array}{l}\text { Don't know or haven't } \\
\text { heard of them }\end{array}$ & $P^{\dagger}$ \\
\hline Smokers and recent ex-smokers $(n=1721)$ & $20 \%(337)$ & $51 \%(867)$ & $16 \%(274)$ & $14 \%(234)^{\ddagger}$ & \\
\hline Ever used NRT or SSMs & & & & & $<0.001$ \\
\hline Yes & $31 \%(179)$ & $55 \%(324)$ & $9 \%(50)$ & $5 \%(32)$ & \\
\hline No & $14 \%(158)$ & $48 \%(541)$ & $20 \%(223)$ & $18 \%(196)$ & \\
\hline Used NRT or SSMs in the past year & & & & & $<0.001$ \\
\hline Yes & $35 \%(132)$ & $53 \%(197)$ & $7 \%(27)$ & $5 \%(17)$ & \\
\hline No & $15 \%(203)$ & $50 \%(659)$ & $19 \%(245)$ & $16 \%(211)$ & \\
\hline Smoking status & & & & & 0.2 \\
\hline Daily smokers & $19 \%(268)$ & $51 \%(700)$ & $16 \%(218)$ & $14 \%(197)$ & \\
\hline Non-daily smokers & $18 \%(45)$ & $53 \%(132)$ & $18 \%(44)$ & $12 \%(30)$ & \\
\hline Recent ex-smokers ${ }^{\xi}$ & $31 \%(24)$ & $45 \%(35)$ & $15 \%(12)$ & $9 \%(7)$ & \\
\hline \multicolumn{6}{|l|}{ Daily smokers only ( $n=1383$ ) } \\
\hline Heaviness of Smoking Index score & & & & & 0.007 \\
\hline Low (0-1) & $17 \%(39)$ & $49 \%(115)$ & $14 \%(33)$ & $20 \%(46)$ & \\
\hline Moderate $(2-3)$ & $20 \%(161)$ & $53 \%(416)$ & $14 \%(112)$ & 13\% (103) & \\
\hline Heavy (4-6) & $19 \%(61)$ & 46\% (149) & $22 \%(70)$ & $14 \%(45)$ & \\
\hline
\end{tabular}

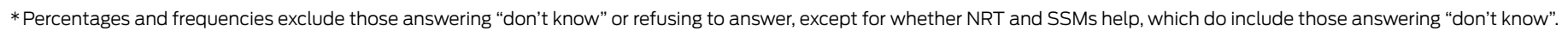

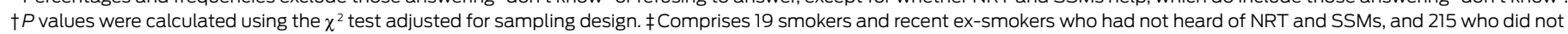
know if they helped smokers to quit. $\$$ Those who had quit $\leqslant 12$ months before.

for the sampling design, using the 35 sites as clusters and the age-sex quotas as strata in Stata 13 (StataCorp) survey [SVY] commands). ${ }^{16} P$ values were calculated for each variable using adjusted Wald tests. However, we used $\chi^{2}$ tests to assess the association of variables with beliefs about whether NRT and SSMs help in quitting, and the association of past use with reasons for not intending to use them in the future. Median durations of NRT use are reported with interquartile ranges (IQRs) and were compared using the non-parametric equality of medians test.

Reported percentages and frequencies exclude those refusing to answer or answering "don't know", except for questions on future interest in NRT or SSM use and whether they help in quitting, which include those answering "don't know". Less than $2 \%$ of smokers and recent ex-smokers answered "don't know" or refused to answer each of the questions analysed here.

\section{Results}

Compared with other daily Australian smokers in the ITC Project, lower proportions of Aboriginal and
Torres Strait Islander daily smokers reported ever using any NRT or SSMs (37\% [515/1379] v 58.5\% [95\% CI, $42.8 \%-72.6 \%]$ ) and having used them in the past year $(23 \%$ [318/1369] v $42.1 \%$ [95\% CI, $29.4 \%-56.0 \%]$ ).

Among all Aboriginal and Torres Strait Islander smokers and recent exsmokers in the TATS project sample, $29 \%(501 / 1700)$ had ever used NRT and $11 \%(193 / 1700)$ had used SSMs. Nicotine patches were the most commonly used, by $24 \%$ (415/1699), followed by varenicline $(11 \% ; 183 / 1699)$, nicotine gum (10\%; 174/1699), lozenges (3\%; 50/1699), and inhalers ( $3 \%$; $50 / 1699)$. Only 1\% (17/1699) had used bupropion.

Of the Aboriginal and Torres Strait Islander smokers and recent ex-smokers who had used NRT within the past year, most had last got it from an Aboriginal medical service $(46 \%$; $99 / 216)$, pharmacy $(31 \% ; 66 / 216)$ or another local health service $(15 \%$; $32 / 216)$, with only $3 \%(6 / 216)$ getting it from an ordinary store. Threequarters $(74 \%$; $161 / 217)$ got their NRT at no cost, including almost all who got it from an Aboriginal medical service (93\%; 92/99) or another local health service $(91 \% ; 29 / 32)$.
Of the Aboriginal and Torres Strait Islander smokers and recent ex-smokers who had used NRT within the past year but were currently not using it, only $9 \%(16 / 174)$ had used it for the recommended period of more than 2 months; ${ }^{.79} 49 \%(85 / 174)$ used it for a week or less and $79 \%(138 / 174)$ for a month or less. The median duration of NRT use was 14 days (IQR, 3-30 days), with no significant differences by HSI score or whether it was free.

Aboriginal and Torres Strait Islander daily smokers who were more dependent, according to the HSI and RACGP criteria, were more likely to have ever used NRT or SSMs than those who were less dependent (Box 1). Fewer non-daily smokers than daily smokers or recent exsmokers had ever used them. These associations were similar but less marked for use in the past year.

Among Aboriginal and Torres Strait Islander smokers who were at least moderately dependant (HSI score $\geqslant 2$ ), the group for whom NRT and SSMs are recommended, those who were socioeconomically advantaged were more likely than the disadvantaged to have ever used NRT or SSMs and to have used them in the past 
4 Interest in using nicotine replacement therapy (NRT) or stop-smoking medicines (SSMs) to help quit smoking in the future among dependent Aboriginal and Torres Strait Islander smokers* $(n=1124)$

\begin{tabular}{|c|c|c|c|c|c|c|c|c|c|c|}
\hline \multirow[b]{3}{*}{ Variable } & \multicolumn{5}{|c|}{ Interested in using NRT in the future } & \multicolumn{5}{|c|}{ Interested in using SSMs in the future } \\
\hline & \multicolumn{3}{|c|}{$\%$ (frequency) $^{\dagger}$} & \multirow{2}{*}{$\begin{array}{l}\text { Odds ratio } \\
(95 \% \mathrm{Cl})^{\ddagger}\end{array}$} & \multirow[b]{2}{*}{$P^{\S}$} & \multicolumn{3}{|c|}{$\%{\text { (frequency) }{ }^{\dagger}}^{\dagger}$} & \multirow{2}{*}{$\begin{array}{l}\text { Odds ratio } \\
(95 \% \mathrm{Cl})^{\ddagger}\end{array}$} & \multirow[b]{2}{*}{$P^{\xi}$} \\
\hline & Yes & No & Don't know & & & Yes & No & Don't know & & \\
\hline All dependent smokers & $54 \%(608)$ & $41 \%(462)$ & $4 \%(47)$ & & & $51 \%(575)$ & $42 \%(470)$ & $7 \%(73)$ & & \\
\hline $\begin{array}{l}\text { Think NRT and SSMs help } \\
\text { smokers to quit }\end{array}$ & & & & & $<0.001$ & & & & & $<0.001$ \\
\hline Not at all & $24 \%(43)$ & $73 \%(132)$ & $4 \%(7)$ & 1.0 & & $23 \%(42)$ & $74 \%(134)$ & $3 \%(6)$ & 1.0 & \\
\hline Somewhat & $59 \%(335)$ & $37 \%(211)$ & $3 \%(19)$ & $\begin{array}{c}4.87 \\
(3.19-7.45)\end{array}$ & & $58 \%(325)$ & $37 \%(209)$ & $5 \%(31)$ & $\begin{array}{c}4.96 \\
(3.18-7.73)\end{array}$ & \\
\hline Very much & $80 \%(177)$ & $18 \%(40)$ & $2 \%(4)$ & $\begin{array}{c}13.58 \\
(8.29-22.26)\end{array}$ & & $74 \%(164)$ & $23 \%(51)$ & $3 \%(7)$ & $\begin{array}{c}10.26 \\
(6.3-16.7)\end{array}$ & \\
\hline $\begin{array}{l}\text { Don't know or haven't } \\
\text { heard of them }\end{array}$ & $36 \%(53)$ & $53 \%(78)$ & $11 \%(17)$ & & & $30 \%(44)$ & $51 \%(75)$ & $20 \%(29)$ & & \\
\hline Ever used NRT or SSMs & & & & & $<0.001$ & & & & & $<0.001$ \\
\hline No & $48 \%(352)$ & $48 \%(354)$ & $5 \%(34)$ & 1.0 & & $48 \%(461)$ & $46 \%(438)$ & $6 \%(62)$ & 1.0 & \\
\hline Yes & $69 \%(255)$ & $29 \%(106)$ & $2 \%(8)$ & $\begin{array}{c}2.42 \\
(1.82-3.22)\end{array}$ & & $75 \%(112)$ & $21 \%(31)$ & $4 \%(6)$ & $\begin{array}{c}3.43 \\
(2.22-5.31)\end{array}$ & \\
\hline $\begin{array}{l}\text { Used NRT or SSMs in the } \\
\text { past year }\end{array}$ & & & & & $<0.001$ & & & & & $<0.001$ \\
\hline No & $49 \%(427)$ & $46 \%(401)$ & $5 \%(41)$ & 1.0 & & $49 \%(499)$ & $45 \%(454)$ & $6 \%(65)$ & 1.0 & \\
\hline Yes & $74 \%(176)$ & $25 \%(60)$ & $1 \%(2)$ & $\begin{array}{c}2.75 \\
(1.95-3.90)\end{array}$ & & $78 \%(72)$ & $17 \%(16)$ & $4 \%(4)$ & $\begin{array}{c}4.09 \\
(2.21-7.57)\end{array}$ & \\
\hline $\begin{array}{l}\text { Heaviness of Smoking Index } \\
\text { score }\end{array}$ & & & & & 0.05 & & & & & $<0.001$ \\
\hline Moderate (2-3) & $56 \%(446)$ & $39 \%(311)$ & $4 \%(34)$ & 1.0 & & $53 \%(418)$ & 41\% (323) & $6 \%(51)$ & 1.0 & \\
\hline Heavy (4-6) & $50 \%(162)$ & $46 \%(151)$ & $4 \%(13)$ & $\begin{array}{c}0.75 \\
(0.56-0.99)\end{array}$ & & $48 \%(157)$ & $45 \%(147)$ & $7 \%(22)$ & $\begin{array}{c}0.83 \\
(0.62-1.09)\end{array}$ & \\
\hline
\end{tabular}

year (Box 2). Use decreased with increasing remoteness and area-level disadvantage, increased with education, and was lower among those who reported being treated unfairly in the past year because they were Indigenous. Use also increased with age and was higher among smokers whose local health service had dedicated tobacco control resources. Those who were socioeconomically disadvantaged were even less likely to use SSMs than NRT (Appendix 2).

Most Aboriginal and Torres Strait Islander daily smokers said NRT and SSMs help smokers to quit: $70 \%$ said they help "very much" or "somewhat", 16\% said "not at all" and $14 \%$ did not know (Box 3). Similarly, the Australian ITC Project reported that $74.2 \%(95 \% \mathrm{CI}, 68.9 \%-78.9 \%)$ of Australian daily smokers agreed that NRT and SSMs would make it easier to quit, $11.0 \%$ (95\% CI, $8.7 \%-$ $13.8 \%$ ) disagreed, and $14.8 \%(95 \%$
CI, $10.8 \%-20.0 \%$ ) neither agreed nor disagreed or did not know.

Having used NRT or SSMs was strongly associated with Aboriginal and Torres Strait Islander smokers believing that they help in quitting. Heavy smokers were more likely to believe that they would not help at all (Box 3).

Dependent Aboriginal and Torres Strait Islander smokers who believed NRT and SSMs would help in quitting and those who had used them (ever or in the past year) were more likely to be interested in using them in the future (Box 4). Frequency of strong urges to smoke and strong cravings on the most recent quit attempt were not associated with interest in future use of NRT and SSMs (data not shown).

The main reasons given by dependent smokers who were not interested in using NRT and SSMs in future were that they were not ready to quit (NRT, 36\% [162/445]; SSMs, 29\% [131/449]), because of side effects (19\% [85/445]; $25 \%$ [114/449]), they did not think they would work (18\% [81/445]; $16 \%$ [73/449]) and they preferred not to use them (16\% [73/445]; 18\% [82/449]). Cost was rarely mentioned as a reason (3\% [15/445]; 2\% [10/449]). There were significant differences between the reasons given by those who had and had not used NRT or SSMs in the past year $(P<0.001)$. Those who had used NRT were more likely than those who had not to say they would not use it in the future because of side effects $(45 \%$ [26/58] v 15\% [59/386]) and were less likely to report not being ready to quit $(12 \%$ [7/58] v $40 \%$ [155/386]).

\section{Discussion}

We found lower use of NRT and SSMs among daily smokers in a 
large nationally representative Aboriginal and Torres Strait Islander sample than among those in the general Australian population. This is consistent with research in various countries that has found that smokers from more disadvantaged groups are less likely to use these medicines. ${ }^{17,18}$ We also found a social gradient of reducing use with increasing disadvantage (including perceived experiences of racism) within the Aboriginal and Torres Strait Islander community. Consistent with previous research, we found this gradient was steeper for the use of varenicline (bupropion accounted for very little of the SSM use) than for NRT.18,19

In recent years, many ACCHSs and their government funders have increased their focus on, and directed significant resources towards, tobacco control and cessation support. Our finding of greater use of SSMs by smokers whose local ACCHS had dedicated tobacco control resources provides some evidence for the effect of these policy decisions. We explore other non-pharmacological cessation support elsewhere in this supplement. ${ }^{20}$

Early research into Aboriginal and Torres Strait Islander smokers' use of SSMs focused on the disincentive of the cost of NRT, and interventions to subsidise or provide free NRT. ${ }^{21-24}$ Covering the costs of treatment has been demonstrated to increase the use of NRT and bupropion in other contexts. ${ }^{25,26}$ Following policy changes, we found that nearly threequarters of participants had got their most recent NRT at no cost, removing this financial impediment to its use. Unlike earlier research, cost was rarely given as a reason in our survey for not intending to use NRT or SSMs in the future. ${ }^{21,23}$ While some smokers are still paying a proportion of the cost, it is reassuring that policies to provide access to free NRT seem to be effectively reaching many Aboriginal and Torres Strait Islander smokers.

It is encouraging that a similar proportion of Aboriginal and Torres Strait Islander daily smokers as those in the broader Australian population think these medicines assist cessation. Further, Aboriginal and Torres
Strait Islander smokers who were more dependent were more likely than the less dependent to have used them, in accordance with current clinical guidelines. However, there is still opportunity to improve their use. The clinical guidelines can be better promoted during the training and ongoing education of clinicians and tobacco control workers, to enable more frequent discussion about them with smokers. There remains a large proportion of Aboriginal and Torres Strait Islander smokers who have never used these medicines, are less likely to think they help and less likely to use them in the future, who could be informed about their effectiveness in assisting quitting. ${ }^{27}$

The frequent use of NRT for much less than the recommended 8 weeks is similar to earlier reports in this population; likewise, the median duration was similar to those found in other research in Australia and elsewhere, particularly the shorter durations reported when NRT is available over the counter rather than by prescription. ${ }^{22,28-31}$ Research into the common reasons for stopping NRT and SSMs (resuming smoking, side effects and the belief that it has already worked) suggests that these are generally legitimate and may not be cause for great concern. For example, data from other ITC Project surveys show that $66 \%$ of those who stopped early because they believed that they no longer needed the medication were still abstinent at 6 months. ${ }^{30}$

There has been a significant increase in the use of SSMs in Australia in recent years, especially associated with the release of varenicline in $2008 .^{32}$ The release of new varieties of NRT and other SSMs has also been shown to be associated with this increase in the total use of SSMs, often with very little compensatory decline in the use of older medicines. ${ }^{19,26,32}$ We found that a variety of types of NRT were used (most commonly patches), as well as varenicline and a small amount of bupropion. The range of NRT formulations and other medicines is likely to increase in the future. ${ }^{3}$ The potential impact of e-cigarettes as an aid to cessation remains unclear and contested. ${ }^{33,34}$

\section{Strengths and limitations}

The main strength of our study is its large national sample of Aboriginal and Torres Strait Islander smokers, providing the first detailed national information about the use of NRT and SSMs in this population. However, it is a non-random, albeit broadly representative, sample, and caution is needed in interpreting the comparisons with the Australian ITC Project sample and in generalising the results to the whole Aboriginal and Torres Strait Islander population. The use of NRT or SSMs in our sample of Aboriginal and Torres Strait Islander people in communities served by ACCHSs may be different to that in communities without access to an ACCHS, who use private general practices. Our self-reported data are probably limited by incomplete recall of past use of NRT and SSMs and quit attempts. The effect of these biases will be to weaken reported associations, leading to greater confidence in the significant associations but requiring caution in the implications of findings of no association.

Acknowledgements: The full list of acknowledgements is available in Appendix 3.

Competing interests: No relevant disclosures.

Provenance: Not commissioned; externally peer reviewed.

Received 17 Feb 2015, accepted 11 May 2015.

1 Australian Bureau of Statistics. Australian Aboriginal and Torres Strait Islander Health Survey: updated results, 2012-13. Canberra: ABS, 2014. (ABS Cat. No. 4727.0.55.006.)

2 Thomas D. National trends in Aboriginal and Torres Strait Islander smoking and quitting, 1994-2008. Aust N Z J Public Health 2012; 36: 24-29.

3 Ellerman A, Ford C, Stillman S (updated by Stillman S). Smoking cessation. In: Scollo MM, Winstanley MH, editors. Tobacco in Australia: facts and issues. 4th ed. Melbourne: Cancer Council Victoria, 2012. http://www.tobaccoinaustralia. org.au/chapter-7-cessation (accessed Mar 2015).

4 Cahill K, Stevens S, Perera R, Lancaster T. Pharmacological interventions for smoking cessation: an overview and network meta-analysis. Cochrane Database Syst Rev 2013; (5): CD009329.

5 Australian Government Department of Health. Supply of PBS medicines to remote area Aboriginal Health Services under the provisions of section 100 of 
the National Health Act 1953. Canberra: DoH, 2014. http://www.health.gov.au/internet/main/ publishing.nsf/Content/C4DC71343F83559BCA25 7BF000204689/\$File/supply-of-pharmaceuticalbenefits-faqs-s100.pdf (accessed Dec 2014).

6 Winstanley M (updated by van der Sterren A, Knoche D). Tobacco use among Aboriginal people and Torres Strait Islanders. In: Scollo MM, Winstanley MH, editors. Tobacco in Australia: facts and issues. 4th ed. Melbourne: Cancer Council Victoria, 2012. http://www.tobaccoinaustralia.org. au/chapter-8-aptsi (accessed Mar 2015).

7 Royal Australian College of General Practitioners. Supporting smoking cessation: a guide for health professionals. Melbourne: RACGP, 2011 [updated July 2014]. http://www.racgp.org.au/yourpractice/guidelines/smoking-cessation (accessed Dec 2014).

8 Department of Health and Ageing. Medicines to help Aboriginal and Torres Strait Islander people stop smoking: a guide for health workers. Canberra: Commonwealth of Australia, 2012.

9 Central Australian Rural Practitioners Association. CARPA standard treatment manual. 6th ed. Alice Springs: Centre for Remote Health, 2014.

10 Thomas DP, Briggs VL, Couzos S, et al. Research methods of Talking About The Smokes: an International Tobacco Control Policy Evaluation Project study with Aboriginal and Torres Strait Islander Australians. Med J Aust 2015; 202 (10 Suppl): S5-SI2.

11 Couzos S, Nicholson AK, Hunt JM, et al. Talking About The Smokes: a large-scale, communitybased participatory research project. Med $\mathrm{J}$ Aust 2015; 202 (10 Suppl): S13-S19.

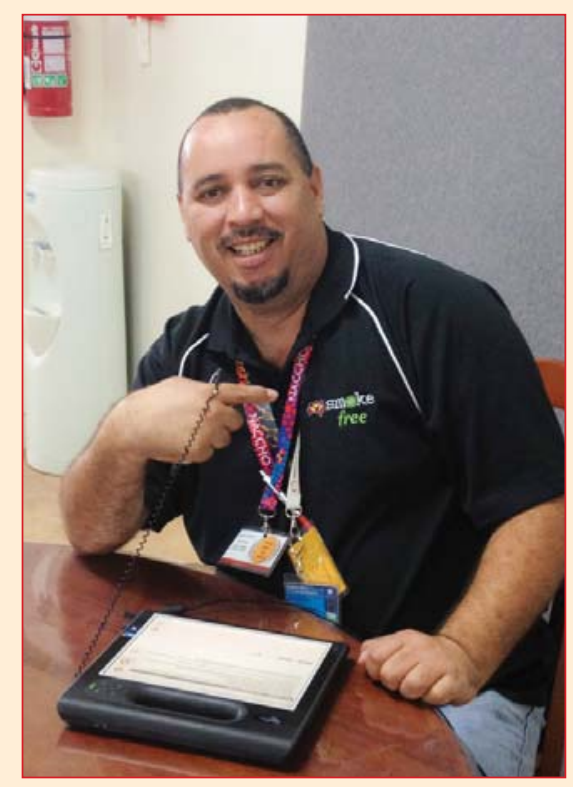

Local research assistant Trevor Philpott from Mamu Health Service, Innisfail, Queensland.
12 International Tobacco Control Policy Evaluation Project. Surveys. http://www.itcproject.org/ surveys (accessed Mar 2015).

13 Heatherton TF, Kozlowski LT, Frecker RC, et al. Measuring the heaviness of smoking: using selfreported time to the first cigarette of the day and number of cigarettes smoked per day. Br J Addict 1989; 84: 791-799.

14 Cooper J, Borland R, Yong HH, et al. To what extent do smokers make spontaneous quit attempts and what are the implications for smoking cessation maintenance? Findings from the International Tobacco Control Four country survey. Nicotine Tob Res 2010; 12 Suppl: S51-S57.

15 Borland R, Yong HH, Balmford J, et al. Motivational factors predict quit attempts but not maintenance of smoking cessation: findings from the International Tobacco Control Four country project. Nicotine Tob Res 2010; 12 Suppl: S4-S11.

16 StataCorp. Stata survey data reference manual: release 13. College Station, Tex: StataCorp, 2013. http://www.stata.com/manualsl3/svy.pdf (accessed Apr 2015)

17 Scollo M, Siahpush M (updated by Pearce M). Smoking and social disadvantage. In: Scollo MM, Winstanley MH, editors. Tobacco in Australia: facts and issues. 4th ed. Melbourne: Cancer Council Victoria, 2012. http://www.tobaccoinaustralia.org. au/chapter-9-disadvantage (accessed Mar 2015).

18 Kasza KA, Hyland AJ, Borland R, et al. Effectiveness of stop-smoking medications: findings from the International Tobacco Control (ITC) Four Country Survey. Addiction 2013; 108: 193-202.

19 Fix BV, Hyland A, Rivard C, et al. Usage patterns of stop smoking medications in Australia, Canada, the United Kingdom, and the United States:

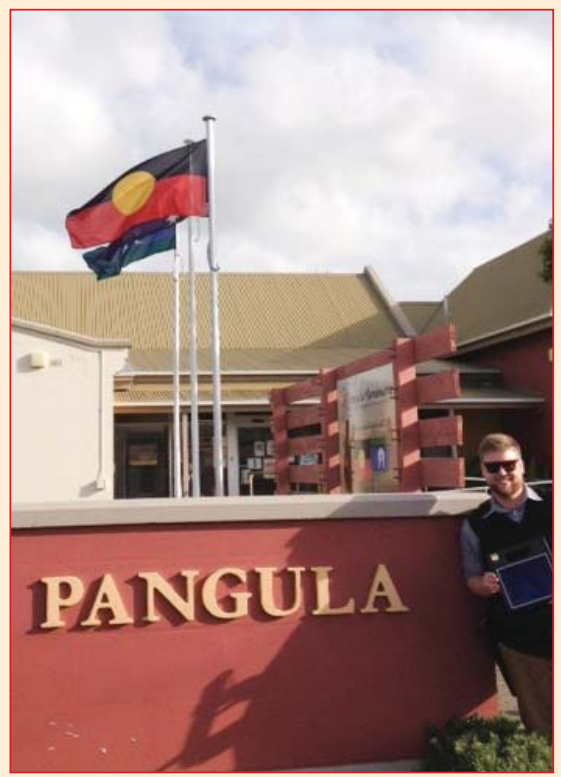

Local research assistant Nick Wilson at Pangula Mannamurna Health Service, Mt Gambier, South Australia findings from the 2006-2008 International Tobacco Control (ITC) Four Country Survey. Int J Environ Res Public Health 2011; 8: 222-233.

20 Thomas DP, Bennet PT, Briggs VL, et al. Smoking cessation advice and non-pharmacological support in a national sample of Aboriginal and Torres Strait Islander smokers and ex-smokers. Med J Aust 2015; 202 (10 Suppl): S73-S77.

21 Lindorff KJ. Tobacco: time for action. National Aboriginal and Torres Strait Islander Tobacco Control Project. Final report. Canberra: National Aboriginal Community Controlled Health Organisation, 2002.

22 Ivers RG, Farrington M, Burns CB, et al. A study of the use of free nicotine patches by Indigenous people. Aust N Z J Public Health 2003; 27: 486-490.

23 Johnston V, Thomas DP. What works in Indigenous tobacco control? The perceptions of remote Indigenous community members and health staff. Health Promot J Austr 2010; 21: 45-50.

24 DiGiacomo M, Davidson PM, Davison J, et al. Stressful life events, resources, and access: key considerations in quitting smoking at an Aboriginal Medical Service. Aust N Z J Public Health 2007; 31: 174-176.

25 Reda AA, Kotz D, Evers SM, van Schayck CP. Healthcare financing systems for increasing the use of tobacco dependence treatment. Cochrane Database Syst Rev 2012; (6): CD004305.

26 West R, DiMarino ME, Gitchell J, McNeill A. Impact of UK policy initiatives on use of medicines to aid smoking cessation. Tob Control 2005; 14: 166-171.

27 Vogt F, Hall S, Marteau TM. Understanding why smokers do not want to use nicotine dependence medications to stop smoking: qualitative and quantitative studies. Nicotine Tob Res 2008; 10: 1405-1413.

28 Paul CL, Walsh RA, Girgis A. Nicotine replacement therapy products over the counter: real-life use in the Australian community. Aust N Z J Public Health 2003; 27: 491-495.

29 Burns EK, Levinson AH. Discontinuation of nicotine replacement therapy among smoking-cessation attempters. Am J Prev Med 2008; 34: 212-215.

30 Balmford J, Borland R, Hammond D, Cummings $\mathrm{KM}$. Adherence to and reasons for premature discontinuation from stop-smoking medications: data from the ITC Four-Country Survey. Nicotine Tob Res 2011; 13: 94-102.

31 Hyland A, Rezaishiraz H, Giovino G, et al. Overthe-counter availability of nicotine replacement therapy and smoking cessation. Nicotine Tob Res 2005; 7: 547-555.

32 Cooper J, Borland R, Yong HH. Australian smokers increasingly use help to quit, but number of attempts remains stable: findings from the International Tobacco Control Study 2002-09. Aust N Z J Public Health 2011; 35: 368-376.

33 McRobbie H, Bullen C, Hartmann-Boyce J, Hajek P. Electronic cigarettes for smoking cessation and reduction. Cochrane Database Syst Rev 2014; (12): CD010216.

34 E-cigarettes - aid to smoking cessation or smokescreen? Lancet 2014; 384: 829 ․ 